\title{
Disparities in Hospital Capacities and Efficiency of Computer-based Health Insurance Claims Processing
}

\author{
Alvin B. Caballes, ${ }^{1}$ Gene A. Nisperos ${ }^{1}$ and Philip C. Zuniga ${ }^{2}$ \\ ${ }^{1}$ College of Medicine, University of the Philippines Manila \\ ${ }^{2}$ Department of Computer Science, University of the Philippines Diliman
}

\begin{abstract}
Background. The Philippine Health Insurance Corporation (PhilHealth) has adopted several computer-based systems to enhance claims processing for hospitals.

Objectives. This study sought to determine the efficiency gains in the processing of PhilHealth claims following the introduction of computer-based processing systems, taking into account differences in hospital characteristics.

Methods. Data were obtained from a survey conducted among 200 hospitals, and their corresponding 2014 claims figures as provided by PhilHealth. Summary descriptive statistics of hospital capacities (ownership, service level, and utilization of PhilHealth computer systems) and claims outcomes (claims rejection rates, as well as length of claims processing times for hospitals and with PhilHealth) were generated. Multivariate regression analysis was done using claims outcomes as dependent variables, and hospital capacities as independent variables.
\end{abstract}

Results. Nearly a quarter of the surveyed hospitals did not utilize any of PhilHealth's computer-based claims systems. Utilization was lowest for primary as well as public facilities. Among those that used the systems, most employed the on-line membership verification program. The mean claims rejection rate was $3.81 \%$. Claims processing by hospitals took an average of 35 days, while PhilHealth required 40 days from receipt of claims to release of reimbursement. Regression analysis indicated that facilities which utilized computers as well as private hospitals had significantly lower claims rejection rates $(p<0.05)$. The claims processing duration was significantly shorter among private facilities.

Conclusions. Private hospitals are able to process claims and obtain reimbursements faster than public facilities, regardless of the use of PhilHeath's computer-based systems. PhilHealth and public hospitals need to optimize claims processing arrangements.

Key Words: administrative claims, healthcare electronic data processing, insurance claims processing, Philippines

\section{INTRODUCTION}

Given the multiplicity of transactions involving many clients on an almost uninterrupted basis, yet still centered on finite options and processes, health insurance claims management can intuitively be made more efficient by computerized systems. The international experience with electronic-based systems in health insurance in general, and claims processing in particular, is well documented. The United States's health care system may be considered a bellwether, having been historically criticized for its deteriorating administrative system. ${ }^{1}$ Electronic claims submission and monitoring were expedited with the passage of the Health Information Portability and Accountability Act (HIPA) in $1996 .{ }^{2}$ By 2011, 93\% of electronicallysubmitted claims were processed within two weeks (compared to $79 \%$ for paper-based claims), with $79 \%$ of 
such claims being automatically adjudicated, at an average cost of US $\$ 0.99$ per claim (as opposed to US $\$ 3.99$ for delayed claims). ${ }^{3}$ A similar trend has been reported with the New England Healthcare Electronic Data Interchange Network (NEHEN), with administrative costs reduced from US $\$ 5.00$ to US $\$ 0.29$ per transaction. ${ }^{4}$ The utilization of ICT and claims processing has also been reported in other countries. ${ }^{5,6,7}$ Caveats have been raised, as converting to electronic systems require substantial investments which may not be readily matched by the benefits that accrue to individual institutions. ${ }^{8,9,10}$ Government intervention may therefore be needed to jump-start the implementation of these systems.

The Philippines has had a social health insurance system since 1969. Nonetheless, it was only recently when electronic transactions were introduced, partially replacing some of the manual processes in the claims systems. The actual impact of these initiatives, considering the geographic constraints as well as discrepant institutional capacities across the country, has not been assessed - and an elucidation of these may offer lessons for the Philippines as well as other developing countries and their social health insurance systems.

The Philippine Health Insurance Corporation (PhilHealth) is the government-owned corporation that is responsible for administering the country's National Health Insurance Program (NHIP). PhilHealth financing is directly channelled to institutional providers (health care institutions, or HCIs, in PhilHealth parlance). There are about 6,000 PhilHealth-accredited HCIs in the country, a fourth of which are hospitals. The bulk of PhilHealth funds go to hospitals to reimburse inpatient expense claims. ${ }^{11}$ Hospitals can be categorized in terms of their service level (primary, secondary or tertiary, in accordance with the licensing standards of Department of Health, or DOH), as well as ownership. The latter, in particular, significantly bear upon the facilities' operational capacities. Public facilities are administered either by the $\mathrm{DOH}$, local governments, or other public institutions (such as public universities) - with each subset having different governance and operational milieus. Primary level as well as privately-owned facilities respectively comprise $69 \%$ and $63 \%$ of the hospitals in the country. While the average bed capacity of primary hospitals is 32 , also included in this category are five- and ten-bed capacity infirmaries. ${ }^{12}$

PhilHealth's reach has been expanding in the intervening years. From 2011 to 2014, there were about 900,000 additional claims filed each year with PhilHealth. ${ }^{11,13,14,15}$ The annual increments in benefit payments for the same period averaged $\mathrm{PhP} 14$ billion, with a total of $\mathrm{PhP} 78$ billion disbursed in 2014. Operational expenditures have likewise risen at a rate of around PhP 320 million per year, with the 2014 figure at PhP 5 billion. Given its expanding membership and provider base as well as rapidly growing financial obligations, there is a greater impetus for PhilHealth to improve the efficiency of its claims-related transactions.
PhilHealth has adopted several measures to streamline its transactions with its various stakeholders, including the introduction of several electronic systems.

In 2011, PhilHealth launched its e-Claims Project to enable the online submission of claims by provider hospitals. The e-Claims Project had three phases: Claims Eligibility Web Service (CEWS), Electronic Claims Submission (ECS), and Claims Status Verification/Payment (CSV). ${ }^{16}$ In 2012, the HCI Portal was introduced as a parallel on-line eligibility authentication system specifically for indigents who qualified for subsidized NHIP enrolment under the Sponsored Program of PhilHealth. ${ }^{17}$ The use of the latter was subsequently extended to general membership verification, and came to supersede the further deployment of the e-Claims systems. Concurrently, the corporation undertook other program and operational initiatives. These included case rate-based reimbursements - which markedly reduced the amount of inputs for claims filing - as well as on-line point-of-service membership enrolment arrangements for indigents (On-Site Rapid Enrolment system, or ORE). ${ }^{11}$

Despite these developments, there remain substantial challenges to ICT-based transactions. Considerable constraints arise from variances in hospital accessibility and capacities. Lower-tier facilities, for instance, can be anticipated to not have the necessary physical and staff resources for such engagements. There is thus a need to determine how these circumstances bear upon the efficiency of claims processing related to PhilHealth's computer-based systems.

\section{OBJECTIVE}

This study aimed to describe the differences in capacities of hospitals and assess the extent to which these, together with their use of the relevant PhilHealth electronic systems, have influenced the efficiency of claims processing.

\section{METHODS}

The research protocol was developed in consultation with $\mathrm{DOH}$ and PhilHealth officials and subsequently approved by the ERB of the University of the Philippines Manila. The original proposal was for a more extensive study, which involved the conduct of focused group discussions and interviews. These qualitative aspects have been excluded from the present report. Data were obtained from a mailed survey involving a stratified and randomly selected sample of 350 hospitals. Stratification was based on regional location, service level, and ownership of the hospitals, with the sample size compatible with a $95 \%$ confidence interval. The survey included, among other items, checklists for technical specifications as well as extent of ICT use (including the use of the HCI Portal, e-Claims, and other PhilHealth ICT transaction systems). The practicability of the survey tool was previously validated with a selected group of hospital administrators. The definitive tool was reproduced and sent 
Table 1. Frequency distribution (percentage) of hospital survey respondents, by ownership type and service level

\begin{tabular}{cccccc} 
& Hospital Category & \multicolumn{4}{c}{ Ownership } \\
\cline { 2 - 6 } & Primary & Private & Public, non-DOH & Public, DOH & Total \\
Level & Secondary & $35(32.5 \%)$ & $44(22.0 \%)$ & $9(4.5 \%)$ & $118(59.0 \%)$ \\
& Tertiary & $38(19.0 \%)$ & $9(4.5 \%)$ & $6(3.0 \%)$ & $53(26.5 \%)$ \\
& Total & $9(4.5 \%)$ & $3(1.5 \%)$ & $17(8.5 \%)$ & $29(14.5 \%)$ \\
\hline
\end{tabular}

by private courier and, for localities unreachable by this service, via special delivery mail to the selected hospitals. Transmittal was carried out in several batches over the first two weeks of June, 2015. The institutional informed consent terms were stated in the included introductory letter from the lead investigator. Stamped return-addressed envelopes were provided in the mailed packets. Follow-ups were made by phone or e-mail starting two weeks after the transmittal of the survey forms. Likewise, the assistance of the regional PhilHealth and DOH offices was sought, so as to verify receipt of the mailed survey and encourage response. Hospitals were also given the option to participate electronically, through a Google-based online site with an identical version of the survey form. Only those which responded within a month after the mailing of the survey were included in the study.

Additionally, the corresponding 2014 claims and reimbursement figures for each of the responding facilities were culled from data obtained from PhilHealth. The data so collected included the number of filed claims per year, number and monetary value of reimbursed claims, and duration of claims processing. The variables for the claims data were defined as follows:

Filed claims refers to the total number of claims filed by a hospital with PhilHealth for 2014;

Valid claims refers to the total number of claims filed by a hospital which were accepted for reimbursement by PhilHealth for 2014;

Claims leakage refers to the percentage of a hospital's filed claims which were not reimbursed by PhilHealth, and was arrived at using the following formula:

$$
\text { Claims leakage }=\frac{\text { filed claims }- \text { valid claims }}{\text { filed claims }} \times 100 \%
$$

Actual reimbursement refers to the total amount, in peso terms, released by PhilHealth as reimbursement for the claims filed by a hospital for 2014;

Claims lag refers to the mean number of days from discharge to the filing of the corresponding claim with PhilHealth for all patients handled by respective hospitals for 2014; and

Reimbursement lag refers to the mean number of days from the filing of a patient's claim with PhilHealth to the issuance of the corresponding authorization for the release of reimbursement for all patients handled by respective hospitals for a specified year.

Responses from returned survey forms were collated and encoded in an electronic spreadsheet. The claims- related figures from PhilHealth as well as those for the generated variables were added on to selected data items (e.g., utilization of PhilHealth ICT modalities) obtained from the corresponding hospitals. Descriptive statistics were drawn from the integrated data table. Stata 10 was used for the regression analysis. The equations which were formulated considered claims outcomes data (claims leakage, claims lag, and reimbursement lag) as each being function of hospitals' organizational characteristics (ownership type and service level) and ICT capacities (in terms of employment of computers for PhilHealth transactions). The claims outcome parameters were the surrogate measures for gauging the effectiveness of the PhilHealth claims process.

\section{RESULTS}

In all, 200 hospitals accomplished and returned the survey forms within the prescribed period, yielding a 57\% response rate (consistent with a $90 \%$ confidence interval). The distribution of the respondent hospitals is shown in Table 1. Primary level as well as private hospitals comprised the majority of these facilities. Nonetheless, the response rate for primary facilities, at $58 \%$, was the lowest compared to those for other hospital categories. During the course of the survey, the administrators of several primary level hospitals had directly called the investigators to state their preference for not participating in the survey. They claimed that their institutions did not even use computers such that the study therefore should not involve them.

The range and extent of adoption by hospitals of the various $\mathrm{PhilHealth}$ computer-based systems and applications is shown in Table 2 . The items are not mutually exclusive, in that several systems could have been concurrently utilized by any single institution. Likewise, not all of the hospitals that reported using computers for PhilHealthrelated transactions identified which actual application they employed (despite being specifically queried for this in the

Table 2. Hospitals' use of computers for PhilHealth-related processes

\begin{tabular}{lc} 
Computer use & $\begin{array}{c}\text { Number of } \\
\text { hospitals }\end{array}$ \\
\hline Membership verification by HCI Portal & 136 \\
Determination of ICD and RVS* codes & 119 \\
Accomplishment of PhilHealth claim forms & 68 \\
Accounting of PhilHealth-related funds 56 & 56 \\
Membership enrolment and verification by ORE & 35 \\
\hline
\end{tabular}

${ }^{*}$ Relative value scale, used as basis for the reimbursement schedules for procedural interventions 
Table 3. Summary statistics of covered hospitals, categorized by service level and ownership

\begin{tabular}{|c|c|c|c|c|c|c|c|}
\hline \multirow{2}{*}{\multicolumn{2}{|c|}{ Hospital type }} & \multicolumn{3}{|c|}{ Service level } & \multicolumn{3}{|c|}{ Ownership } \\
\hline & & I & II & III & Private & Public, non-DOH & Public, DOH \\
\hline Number & & 118 & 53 & 29 & 112 & 56 & 32 \\
\hline \multirow[t]{2}{*}{ Computer use } & (\% frequency among survey item responders) & $66.67 \%$ & $88.00 \%$ & $82.14 \%$ & $81.82 \%$ & $56.60 \%$ & $78.13 \%$ \\
\hline & Total count of filed claims & 366,378 & 412,992 & $1,050,891$ & 500,538 & 358,179 & 430,628 \\
\hline \multirow{2}{*}{ Claims amounts } & Average count of valid claims & 2,986 & 7,609 & 17,145 & 4,373 & 6,142 & 13,093 \\
\hline & Average reimbursement (million $\mathrm{PhP}$ ) & 30.37 & 81.86 & 236.24 & 48.67 & 66.81 & 174.41 \\
\hline \multirow{3}{*}{ Claims outcomes } & Average claims leakage & $4.43 \%$ & $3.25 \%$ & $2.28 \%$ & $3.16 \%$ & $5.25 \%$ & $3.56 \%$ \\
\hline & Average claims lag (days) & 34.36 & 34.58 & 41.38 & 28.70 & 43.39 & 45.13 \\
\hline & Average reimbursement lag (days) & 40.34 & 41.13 & 35.21 & 38.46 & 42.60 & 39.88 \\
\hline
\end{tabular}

Table 4. Regression results for selected claims processing parameters

\begin{tabular}{|c|c|c|c|c|c|c|c|}
\hline \multicolumn{2}{|c|}{ Dependent variable } & \multicolumn{2}{|c|}{ Claims leakage } & \multicolumn{2}{|c|}{ Claims lag } & \multicolumn{2}{|c|}{ Reimbursement lag } \\
\hline & R-squared & \multicolumn{2}{|c|}{0.0809} & \multicolumn{2}{|c|}{0.322} & \multicolumn{2}{|c|}{0.0405} \\
\hline \multicolumn{2}{|c|}{ Independent variables } & Coefficient & $P>t$ & Coefficient & $P>t$ & Coefficient & $P>t$ \\
\hline \multirow{2}{*}{ Level } & Secondary & $(0.01)$ & 0.522 & 1.83 & 0.366 & 1.48 & 0.564 \\
\hline & Tertiary & $(0.02)$ & 0.061 & 2.33 & 0.408 & $(6.77)$ & 0.060 \\
\hline \multirow{2}{*}{ Ownership } & Public, DOH & (0.00) & 0.745 & 0.13 & 0.966 & 1.65 & 0.661 \\
\hline & Private & $(0.02)$ & 0.048 & $(15.75)$ & - & (2.88) & 0.262 \\
\hline ICT & Computerized processing & $(0.02)$ & 0.049 & 2.42 & 0.224 & $(2.53)$ & 0.317 \\
\hline Constant & & 0.06 & - & 41.53 & - & 43.52 & - \\
\hline
\end{tabular}

survey form). Among those that responded, the most widely used were the on-line membership enrolment or verification systems (HCI Portal in particular, with a few mentioning ORE). The only other Internet-based application was the verification of members' remaining benefits, which are actually performed for the hospitals by dedicated PhilHealth staff that had separate web access. The other computerized applications are for the facilitation of the accomplishment of claim forms (which are then manually transmitted to Philhealth).

Descriptive statistics for the responding hospitals are provided in Table 3, broken down according to hospital service level and ownership type. The use of computers for PhilHealth-related transactions was not universal. Based on the survey results, this was lowest among primary as well as non-DOH public hospitals. From the service level perspective, tertiary hospitals expectedly had the most claims filed and reimbursements due, in aggregate and average terms. While private hospitals, as a group, filed the most number of claims in 2014, the claims and reimbursement figures were, on an average basis, lower than those of $\mathrm{DOH}$ hospitals.

In terms of claims outcomes, the mean value for Claims Leakage was 3.81\%, with Claims and Reimbursement Lags at 35 and 40 days, respectively. Primary as well as non-DOH public facilities had higher average Claims Leakage rates. Tertiary and government hospitals had average Claims Lag periods exceeding the over-all mean.

The results of the multivariate regression analysis are listed in Table 4. Facilities which utilized computers for processing Philhealth claims as well as private hospitals had statistically significantly lower claims rejection rates $(\mathrm{p}<0.05)$. Private hospitals also had statistically significantly shorter Claims Lag, with a reduction of nearly 16 days. Tertiary facilities were associated with lower Reimbursement Lag, but this was not statistically significant.

\section{DISCUSSION}

The overall survey response rate may be considered as acceptable based on current literature. ${ }^{19,20}$ There were limitations in this study, including those inherent in using mailed survey for data collection. There were divergent response rates across regions and even HCI types. There may be biases, in terms of which institutions opted to respond, and how these answered the survey form, among others. A considerable proportion of targeted primary hospitals opted not to participate, with a few indicating their nonutilization of computers as the main reason. Smaller facilities may be presumed to not have the capital or personnel to be able to avail of computer systems, much less undertake online transactions. The study's results and inferences should be weighed in the light of its various limitations.

The study used the proportion of rejected claims, or claims leakage, as well as processing times to assess the efficiency of PhilHealth claims processing. Other parameters could have been utilized, such as transaction costs. ${ }^{3,4,7}$ Such would have, however, involved more detailed financial data which could not be readily obtained from either PhilHealth or hospital administrators. Likewise, annualized data were utilized in the analysis, which presumes that the filing and reimbursement for the same claims occurred within the same year. More realistically, some claims were filed in the previous year, yet the processing if not actual reimbursement would have been accomplished in the succeeding year thereby implicitly affecting the Claims Leakage values. Nonetheless, not using the annual time frame would have 
necessitated more detailed and rigorous segregation of claims that was not feasible given the resource constraints of the research.

Claims may be rejected for a variety of reasons, ranging from inadequately accomplished forms to outright fraud. A basic requirement for the filing of PhilHealth claims is the prior confirmation of the membership (or dependent) status of the beneficiary. This used to entail the manual issuance of the pertinent certification from the local PhilHealth office (which may not be easily reached from remote areas), that then had to be hand-carried back to the hospital by the member. Claims that are filed without eligibility status verification, or false documentation, run the risk of being denied by PhilHealth. The hospital-based PhilHealth online verification systems address this bottleneck. In the same way, modalities that ensure the accurate accomplishment of claim forms - such as the corresponding Philhealth computer applications - can be expected to reduce the incidence of rejected claims. The results of the study indicate that hospitals' use of computer-based systems, on-line verification being one of these, are indeed associated with reduction, by a third, of claims leakage.

Private hospitals, independently, also have significantly lower Claims Leakage rates. Such suggests that these facilities are inherently more efficient in accomplishing claims. Being mostly for-profit institutions, these hospitals have all the incentive to minimize claims loss and thereby hasten and maximize reimbursements. Private institutions conceivably have been able to commit assets to PhilHealth claims processing, while public hospitals were either not so inclined, or did not have the resources to do so. The inherent variations in the management systems with regard to private and government hospitals, and their relationship with public financing of in-patient expenses, has been previously described. ${ }^{21}$ The present study further highlights these differences and their operational implications.

The results indicate that private hospitals also singularly have a significant advantage with regard to Claims Lag. A reduction by a third of the calculated total hospital claims processing time is enjoyed by these facilities. The same rationale as that for Claims Leakage can be surmised to apply. Private facilities would seem to have honed their systems to ensure the efficient handling of PhilHealth claims. Computerized processes do not have any significant association for this measure.

Tertiary hospitals had the shortest Reimbursement Lag, but this relationship was not shown to be statistically significant with the regression equation that was used. The tendency nonetheless suggests that these facilities, with the greater bulk of filed claims (and therefore requiring more time to process within the hospitals themselves, thus the higher Claims Lag) could have had their claims more expeditiously handled by PhilHealth.

PhilHealth stated in its 2014 Annual Report that the "Turn Around Time (TAT)", or the average duration for its processing of claims, was reduced to 39 days. ${ }^{11}$ It is unclear, though, what the endpoint of TAT actually was, given PhilHealth's conflicting definitions. ${ }^{18}$ Nevertheless, the reduced duration for claims processing was attributed to several interventions, including the use of computer-based and on-line systems. While the metric may be synonymous with the Reimbursement Lag assessed in this study, sole reliance on TAT as an indicator of claims processing efficiency has its drawbacks. The segregation of the processing period into the parts which are primarily within the greater control of specific stakeholders as was done in this study more accurately gauges the corresponding operational efficiencies. As the results of the study show, the Claims lag (which concerns hospital-centred processing) was nearly as long as the Reimbursement lag (which covers the claims and reimbursement processing under PhilHealth's control). Even then, these two parameters still did not account for the entire claims processing period, as the time from the authorization of the reimbursement to the actual receipt of these funds by hospitals was not included.

At the time that the survey for this study was done, the computer-based PhilHealth applications, including the online systems, were accessible to the hospitals for more than a year. In particular, the HCI Portal was widely in use, and had supplanted the earlier e-Claims systems. The latter, while having more extensive functions, was, for undisclosed reasons, unilaterally discontinued by PhilHealth. The default PhilHealth electronic systems - HCI Portal, and, to a lesser extent, ORE - only enabled better beneficiary authentication. Thus, the relationship of these systems to the reduction of Claims Leakage is marked. Nonetheless, these, together with the other computer-based PhilHealth applications, do not hasten other downstream claims processes. Their impact on the measured claims processing time has thus not been substantial.

While not directly assessed in this study, the underrepresentation of primary facilities - to the extent that nonavailability if not non-utilization of ICT is contributory to this - suggests that a potentially sizable number of facilities are effectively disenfranchised from benefiting from PhilHealth ICT systems. Even as the efficiency gains from the applications are apparently limited, more prevalent computer usage will be a Pareto improvement and sow the necessary conditions for enhanced claims processing. Mandates or incentives may need to be put in place to foster uniform computer availability and use of the PhilHealh claims modules, among other electronic transaction systems, among hospitals.

The current status of electronic claims processing provide lessons for other entities considering the introduction of similar technologies. Specifically, developing countries or those newly adopting social health insurance systems will need to resolutely determine their overall objectives, and tailor programs and interventions accordingly. While ICT systems offer the promise of promoting efficiency, their 
utilization does not necessarily guarantee this. The present study provides a case in point, wherein the use of electronic processing systems was not associated with a key efficiency measure, that of claims processing time. The narrow functional scope of the utilized applications, together with the intrinsically dissimilar operational milieu of different types of hospitals, restricted their overall effectiveness.

If efficiency gains in claims processing are to be assured, then PhilHealth will have to adopt or enable more comprehensive electronic systems. The re-introduction of the e-Claims Project systems, or an altogether novel yet more inclusive system, should be strongly considered by PhilHealth and its stakeholders. Incentives and financial management systems will also have to be aligned, especially for government facilities, to foster the assumption of more efficient systems, if not cultures, as may presently pervade private hospitals.

\section{CONCLUSIONS}

Nearly a quarter of the hospitals that participated in the study did not utilize any of PhilHealth's computer-based claims process applications and systems. Utilization was lowest for primary as well as non-DOH public facilities. Among those that used the systems, most employed the online membership verification programs. Tertiary hospitals had the largest amount of claims and reimbursements. The efficiency of claims processing was gauged in terms of proportion of rejected claims, as well as processing times. Use of computerbased or on-line systems for PhilHealth claims processing was associated with less invalid claims. Private hospitals also had significantly less rejected claims, as well as shorter claims processing time. The use of existing PhilHealth ICT applications and systems was not significantly associated with reductions in the duration of claims processing.

\section{Acknowledgments}

The production of the manuscript, and the research work on which this is based on, was made possible by funding from the Health Systems Research Management Fund of the $\mathrm{DOH}$, administrative support by staff of the Philippine Council for Health Research and Development (PCHRD), University of the Philippines Manila, and the University of the Philippines Medical Alumni Fund, Inc. (UPMAF). Mr. Benjamin David provided administrative assistance.

\section{Statement of Authorship}

All authors have approved the final version submitted.

\section{Author Disclosure}

All authors have declared no conflict of interest.

\section{Funding Source}

This paper was funded by the Health Systems Research Management Fund of the Department of Health (DOH).

\section{REFERENCES}

1. Woodhandler S, Himmelstein DU. The deteriorating administrative efficiency of the U.S. healthcare system. N Engl J Med.. 1991; 324(18): 1253-8.

2. Herndon P. The drive for electronic claims. Monitor on Psychology. 2003;34(8):28.

3. America's health insurance plans. Rise in electronic claims submission speeds up receipt, processing time [Online]. 2013 [cited 2014 August]. Available from http://www.ahip.org/News/Press-Room/2013/Risein-Electronic-Claims-Submission-Speeds-Up-Receipt,-ProcessingTime.aspx.

4. Halamka J. New England Healthcare EDI Network, The New England approach to HIPAA [Online]. 2013 [cited 2014 September]. Available from www.ehcca.com/presentations/HIPAA2/106.PDF.

5. Alvarez RC. The promise of e-health - a Canadian perspective. EHealth International. 2002;1:4. https://doi.org/10.1186/1476-3591-1-4.

6. Cornwall A. Electronic health records: an international perspective. Health Issues. 2002;73: 19-23.

7. OECD. Improving health sector efficiency: The role of information and communication technologies. 2010.

8. Parente ST. Beyond the hype: a taxonomy of e-health business models. Health Affairs. 2000; 19(6): 89-102. https://doi.org/10.1377/ hlthaff.19.6.89.

9. Bates DW. The quality case for information technology in healthcare. BMC Medical Informatics and Decision Making. 2002; 2:7. https:// doi.org/10.1186/1472-6947-2-7.

10. KleinkeJD.Dot-Gov:Market failure and the creation of a national health information technology system. Health Affairs. 2005;24(5): 1246-1262. https://doi.org/10.1377/hlthaff.24.5.1246.

11. Philippine Health Insurance Corporation (PhilHealth). Great leaps: charting the future of Philippine health care. Annual Report. [Online]. 2014 [cited 2015 September]. Available from http://www.philhealth. gov.ph/about_us/annual_report/ar2014.pdf .

12. Philippine Health Insurance Corporation. List of accredited hospitals as of March 15, 2015. [Online]. 2015 [cited 2015 October]. Available from http://www.philhealth.gov.ph/partners/providers/institutional/ accredited/hospitals_032015.pdf.

13. Philippine Health Insurance Corporation. Kambyo: Shifting gear. Annual Report. [Online]. 2011 [cited 2015 September]. Available from http://www.philhealth.gov.ph/about_us/annual_report/ar2011.pdf .

14. Philippine Health Insurance Corporation. Arangkada: tungo sa kalusugang pangkalahatan. Annual Report. [Online]. 2012 [cited 2015 September]. Available from http://www.philhealth.gov.ph/about_us/ annual_report/ar2012.pdf.

15. Philippine Health Insurance Corporation. Synergizing efforts towards Universal Health Care. [Online]. 2031 [cited 2015 September]. Available from http://www.philhealth.gov.ph/about_us/annual_ report/ar2013.pdf .

16. Philippine Health Insurance Corporation. Implementation of claims eligibility web Service (CEWS) Phase I of e-Claims Project. Circular No. 014-2011. 2011.

17. Philippine Health Insurance Corporation. Guidelines on the implementation of institutional health care provider (IHCP) Portal. Circular No. 002-2012. 2012.

18. Manila Times. PhilHealth exec dismisses backlog allegations - The Manila Times Online. [Online]. 2014 [cited 2014 August]. Available from http://www.manilatimes.net/breaking_news/philhealth-execdismisses-backlog-allegations/.

19. Fincham JE. Response rates and responsiveness for surveys, standards, and the Journal. Am J Pharm Educ. 2008; 72(2):43.

20. Nutty DD. The adequacy of response rates to online and paper surveys: what can be done? Assessment \& Evaluation in Higher Education. 2008. 33(3), 301-14. https://doi.org/10.1080/02602930701293231.

21. Caballes AB, Sollner W, Nanagas J. Financial protection mechanisms for in-patients at selected Philippine hospitals. Social Science and Medicine. 2012; 75(10): 1820-7. https://doi.org/10.1016/j. socscimed.2012.07.027. 